Check for updates

Cite this: RSC Adv., 2018, 8, 26277

\title{
Hexagonal hollow silica plate particles with high transmittance under ultraviolet-visible light $\dagger$
}

\author{
Lailatul Qomariyah, (DD a Aditya F. Arif, (D) ${ }^{b}$ W. Widiyastuti, (D) a Sugeng Winardi, ${ }^{a}$ \\ Shuto Taniguchi ${ }^{\mathrm{b}}{ }^{\mathrm{b}}$ and Takashi Ogi $\left(\mathbb{D}{ }^{* b}\right.$
}

Creating hollow structures is one strategy for tuning the optical properties of materials. The current study aimed to increase the optical transmittance of silica $\left(\mathrm{SiO}_{2}\right)$ particles. To this end, hexagonal-shaped hollow silica plate (HHSP) particles were synthesized from tetraethyl orthosilicate (TEOS) and zinc oxide ( $\mathrm{ZnO}$ ) template particles, using a microwave-assisted hydrothermal method. The size and shell thickness of the HHSP particles could be adjusted by using different TEOS/ZnO molar ratios and different ZnO template sizes, respectively. The optical transmittance of the HHSP particles depended on the shell thickness and particle size. The highest transmittance was $99 \%$ in the ultraviolet and visible region $(300-800 \mathrm{~nm})$ and was exhibited by HHSP particles with the thinnest shell thickness of $6.3 \mathrm{~nm}$. This transmittance was higher than that exhibited by spherical hollow silica particles with a similar shell thickness. This suggested morphologydependent transmittance for the semiconducting material. These preliminary results illustrate the promising features of the HHSP particles and suggest their potential application in future transparent devices.

Received 5th June 2018

Accepted 12th July 2018

DOI: $10.1039 / c 8 r a 04787 a$

rsc.li/rsc-advances reported that higher transmittance was exhibited by hollow $\mathrm{SiO}_{2}$ spheres with smaller cavities and thinner shells. ${ }^{12} \mathrm{~A}$ polarizationdependent response due to the aspect ratio was proposed by Gans theory. ${ }^{11}$ However, such a response provides the opportunity to adjust the optical properties of $\mathrm{SiO}_{2}$ as semiconductor material by tuning the geometry, for example, by creating an anisotropic hollow structure. Many anisotropic structures have been synthesized including nanorods, ${ }^{13-15}$ nanotubes, ${ }^{16-18}$ and nanocages. ${ }^{1,19,20}$ However, this concept has not been well studied in regard to understand the effect of anisotropic structure on the optical properties of semiconductor material such as $\mathrm{SiO}_{2}$.

In this study, we prepared anisotropic hexagonal hollow silica plate (HHSP) particles with high transmittance under ultraviolet (UV) and visible (Vis) light. The HHSP particles were synthesized from tetraethyl orthosilicate (TEOS) using a rapid, surfactant-free synthesis involving microwave irradiation. The microwave irradiation accelerated the hydrolysis and condensation of TEOS on the template surface. The hollow structure was formed using zinc oxide $(\mathrm{ZnO})$ particles as the template, which were easily removed by etching using low-concentration acidic solution. The shell thickness of the HHSP particles could be adjusted by changing the TEOS concentration, which also affected the optical transmittance of the HHSP particles. We compared the optical transmittance of hexagonal hollow structure with spherical hollow structure to study the effect of anisotropic structure on its optical properties.

\section{Materials and methods} University, 1-4-1 Kagamiyama, Higashi-Hiroshima, Hiroshima 739-8527, Japan. E-mail: ogit@hiroshima-u.ac.jp

$\dagger$ Electronic supplementary information (ESI) available. See DOI: 10.1039/c8ra04787a
In a typical synthesis of the HHSP particles, ZnO template particles (Sakai Chemical Industry, Co. Ltd., Osaka, Japan) were 
well dispersed in ethanol by ultrasonicating for $30 \mathrm{~min}$. Ultrapure water, TEOS (99.9\%, Sigma-Aldrich, St. Louis, MO, USA), and ammonia solution (Kanto Chemical Co., Inc., Tokyo, Japan) were then added to the $\mathrm{ZnO}$ dispersion. The resulting mixture was heated under microwave irradiation (Biotage, Uppsala, Sweden) for $1 \mathrm{~h}$ at $80^{\circ} \mathrm{C}$. The resulting particles were separated from the solution by centrifugation at $8000 \mathrm{rpm}$ for $10 \mathrm{~min}$, followed by washing and vacuum drying. Removal of $\mathrm{ZnO}$ was achieved by etching in $0.2 \mathrm{M}$ hydrochloric acid. Complete etching was indicated by a change in the solution colour from milky to semi-transparent. To control the HHSP particle size and shell thickness, the $\mathrm{ZnO}$ size and TEOS/ZnO molar ratio were varied from $0.1 \mu \mathrm{m}$ to $2 \mu \mathrm{m}$ and from 0.2 to 1.125,

Table 1 Characteristics of the $\mathrm{ZnO}$ templates

\begin{tabular}{llll}
\hline ZnO template type & $\begin{array}{l}\zeta \text {-potential } \\
{[\mathrm{mV}]}\end{array}$ & Size $[\mu \mathrm{m}]$ & $\begin{array}{l}\text { Plate thickness } \\
{[\mathrm{nm}]}\end{array}$ \\
\hline A & +14 & 0.1 & 30 \\
$\mathrm{~B}$ & -21 & 0.3 & 80 \\
$\mathrm{C}$ & -21 & 1.0 & 290 \\
$\mathrm{D}$ & -22 & 2.1 & 750
\end{tabular}

respectively. Four types of $\mathrm{ZnO}$ particles were used as templates, as described in detail in Table 1.

The morphologies of the $\mathrm{ZnO}$ template particles, $\mathrm{ZnO}-\mathrm{SiO}_{2}$ core-shell particles, and HHSP particles were examined using field-emission scanning electron microscopy (SEM; S-5000, 20 kV, Hitachi High-Tech. Corp., Tokyo, Japan) and transmission electron microscopy (TEM; JEM-2010, 200 kV, JEOL Ltd., Tokyo, Japan).

The shell thickness and particle size were measured from approximately 200 randomly selected particles observed in the TEM images and SEM images, respectively. The $\zeta$-potentials were determined by dynamic light scattering (DLS; Zetasizer Nano ZSP, Malvern Instruments Ltd., Malvern, U.K.). The measurement of optical transmittance was performed using UV-Vis spectroscopy (UV-3150; Shimadzu Corp., Japan). Fourier-transform infrared (FT-IR) spectra were recorded to investigate the chemical bonding in the particles (IRAffinity1S; Shimadzu Corp., Japan).

\section{Results and discussion}

The formation of the HHSP particles, as illustrated in Fig. 1(a), was initiated by the nucleation of negatively charged TEOS $(-34$ (a)
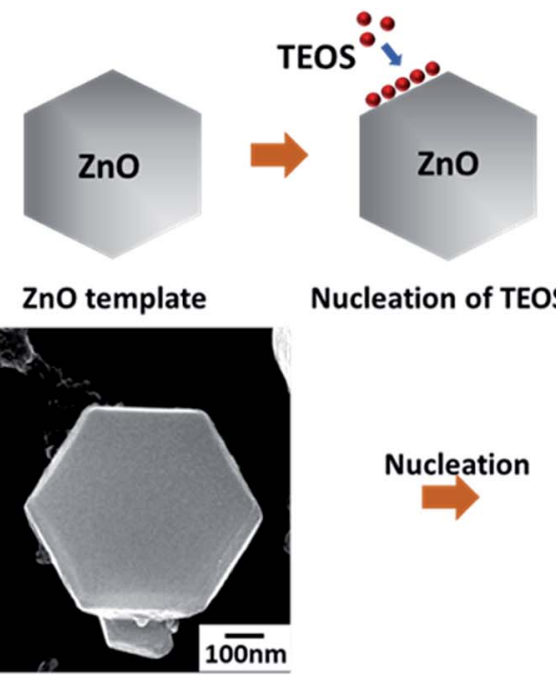

Nucleation of TEOS

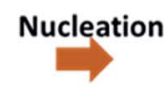

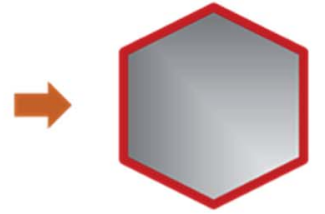

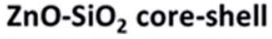
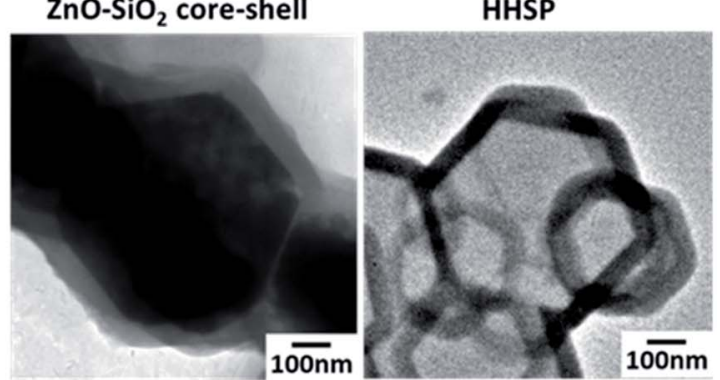

(c)

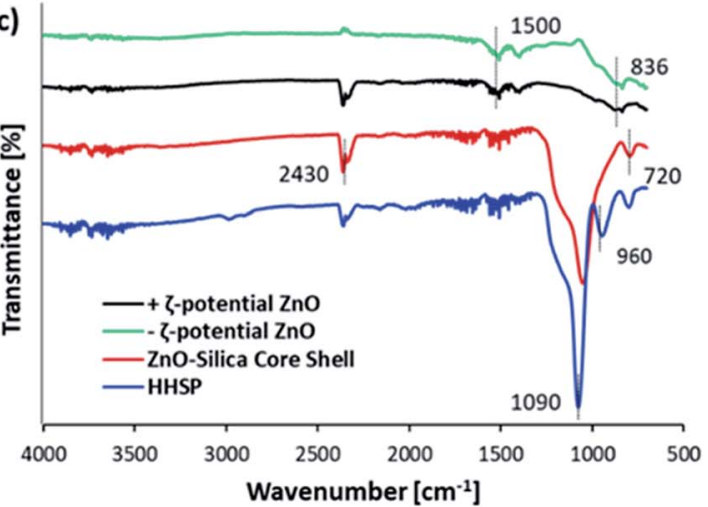

Fig. 1 Schematic of the nucleation of $\mathrm{SiO}_{2}$ on the $\mathrm{ZnO}$ template (a). XRD patterns of $\mathrm{ZnO}, \mathrm{ZnO}-\mathrm{SiO}_{2}$ core-shell, and $\mathrm{HHSP}$ particles (b). FTIR spectra of $\mathrm{ZnO}, \mathrm{ZnO}-\mathrm{SiO}_{2}$ core-shell, and HHSP particles (c). 
(A)

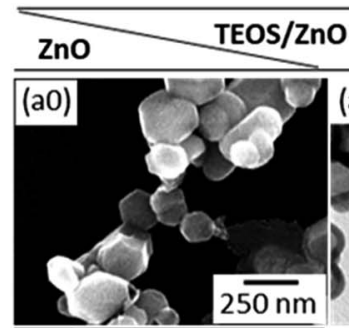

1.125

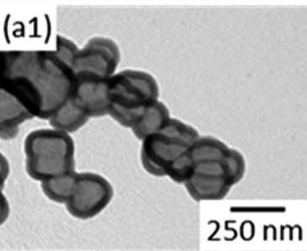

(B)

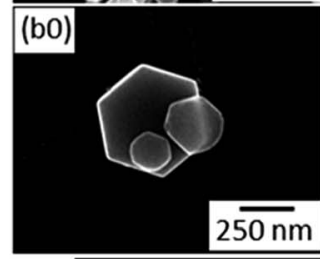

(C)

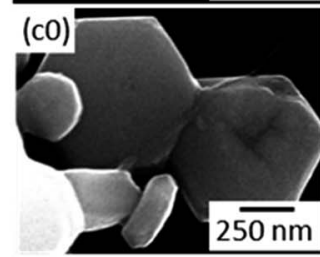

(b1)

(D)

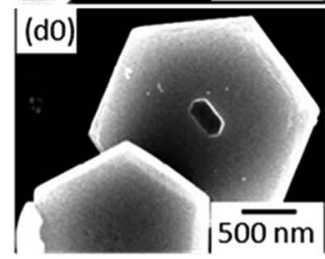

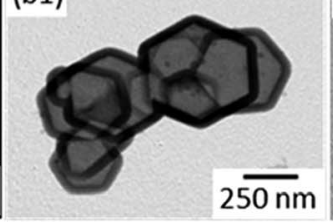
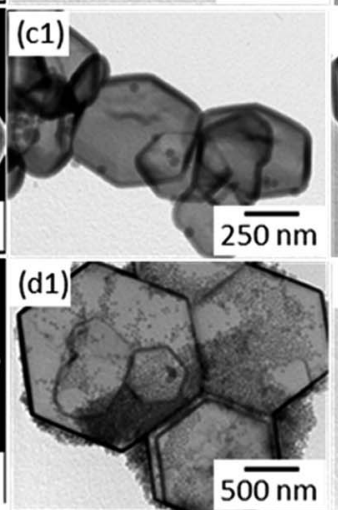

0.75
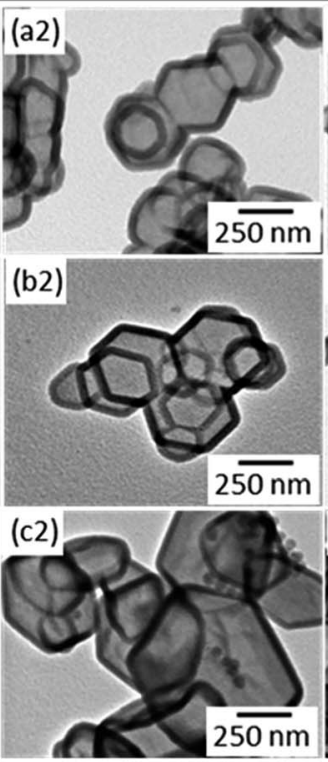

(d2)

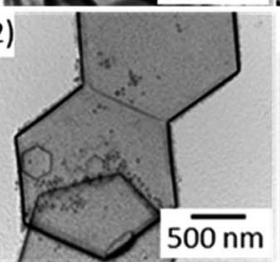

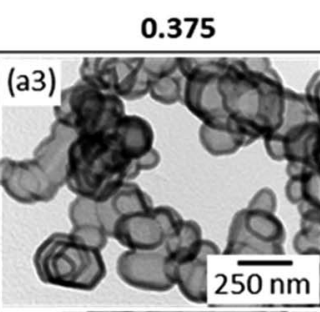

(b3)
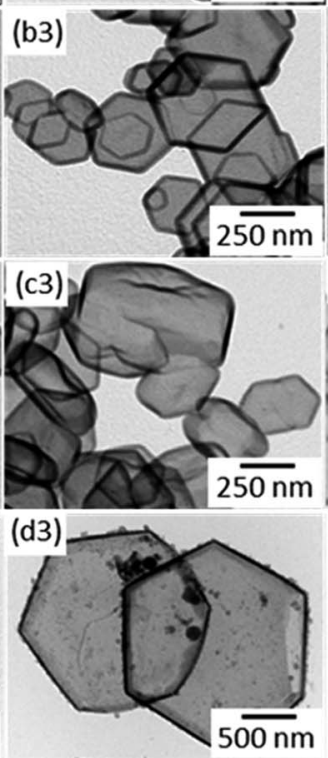

0.2
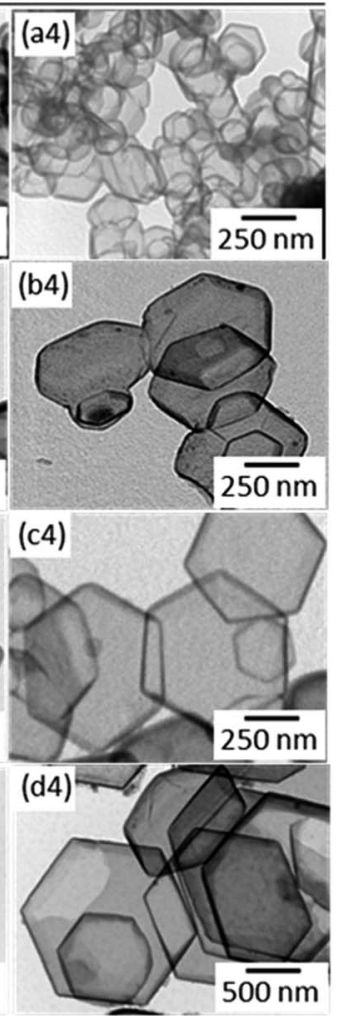

Fig. 2 SEM images of the $\mathrm{ZnO}$ templates (a0-d0), and TEM images of the respective HHSP particles synthesized using TEOS/ZnO molar ratios of 1.125 (a1-d1), 0.75 (a2-d2), 0.375 (a3-d3), and 0.2 (a4-d4).

$\mathrm{mV}$ ) on the ZnO surface. Two different mechanisms could potentially contribute to the nucleation, which are electrostatic interaction and diffusion-controlled heterogeneous nucleation. Electrostatic-driven nucleation was neglected in the current case because nucleation occurred in both negatively and positively charged $\mathrm{ZnO}$, as indicated by the synthesis of HHSP particles using both positively and negatively charged $\mathrm{ZnO}$, as shown in Fig. 2. Thus, the diffusion-controlled nucleation was dominant. This phenomenon can be explained by classical nucleation theory, i.e., heterogenous and homogenous nucleation. Although the current study involved hexagonal-shaped $\mathrm{ZnO}$ as the foreign body, the nucleation principle was similar to that in our previous work involving spherical polystyrene latex as the foreign body. ${ }^{21}$

After the nucleation of $\mathrm{SiO}_{2}$ on the $\mathrm{ZnO}$ surface, TEOS underwent hydrolysis and condensation on the surface of the $\mathrm{ZnO}$ template under basic catalytic conditions in the absence of comonomer, to form the silica shell. The formation of the $\mathrm{SiO}_{2}$ shell was confirmed by XRD analysis, the results of which are shown in Fig. 1(b). All peaks in the XRD pattern of the $\mathrm{ZnO}$ template could be assigned to the wurtzite structure (Zincite, JCPDS no. 5-0664). The ZnO peaks were also present in the XRD pattern of the $\mathrm{ZnO}-\mathrm{SiO}_{2}$ core-shell particles, but with lower intensities. This was consistent with coverage of the $\mathrm{ZnO}$ template by amorphous $\mathrm{SiO}_{2}$. FT-IR spectra confirmed the chemical bonding in the $\mathrm{ZnO}$ template and $\mathrm{ZnO}^{-S_{O}}{ }_{2}$ core- shell particles, as shown in Fig. 1(c). The reduction peaks at around $836 \mathrm{~cm}^{-1}$ and $1500 \mathrm{~cm}^{-1}$ were assigned to the vibration of $\mathrm{Zn}-\mathrm{O}$ bridging bonds. ${ }^{22}$ These peaks were characteristic peaks of the $\mathrm{ZnO}$ template, regardless of the $\mathrm{ZnO}$ surface charge. The sharp peak at around $1090 \mathrm{~cm}^{-1}$ confirmed the presence of $\mathrm{SiO}_{2}$, and the peak near $720 \mathrm{~cm}^{-1}$ was assigned to the asymmetric vibration of the $\mathrm{Si}-\mathrm{O}-\mathrm{Si}$ bridging bonds of the siloxane link in the spectrum of the $\mathrm{ZnO}-\mathrm{SiO}_{2}$ core-shell particles. ${ }^{23}$

After removing the $\mathrm{ZnO}$ template, the $\mathrm{ZnO}$ peak disappeared from the XRD pattern, leaving the peak of amorphous $\mathrm{SiO}_{2}$ at $2 \theta=24^{\circ}$. This confirmed that the $\mathrm{ZnO}$ template was completely removed from the core, resulting in hexagonalshaped hollow silica plate particles. The FT-IR spectrum of the etched sample was consistent with this conclusion. The sharp peak corresponding to silica at around $1090 \mathrm{~cm}^{-1}$ remained in the FT-IR spectrum of the etched sample, while the characteristic peak of ZnO was not observed. A new peak was observed near $960 \mathrm{~cm}^{-1}$ which was due to the asymmetric stretching vibration of the Si-OH bridge of the siloxane link. ${ }^{24}$ Peaks near $2430 \mathrm{~cm}^{-1}$ in the FT-IR spectrum of the etched sample were attributed to hydroxyl groups. ${ }^{22}$

Fig. 2 shows SEM images of the hexagonal plate $\mathrm{ZnO}$ core template particles, and TEM images of HHSP particles synthesized using the respective template. The corresponding SEM images of the HHSP particles are shown in the ESI Fig. S1. $\dagger$ 

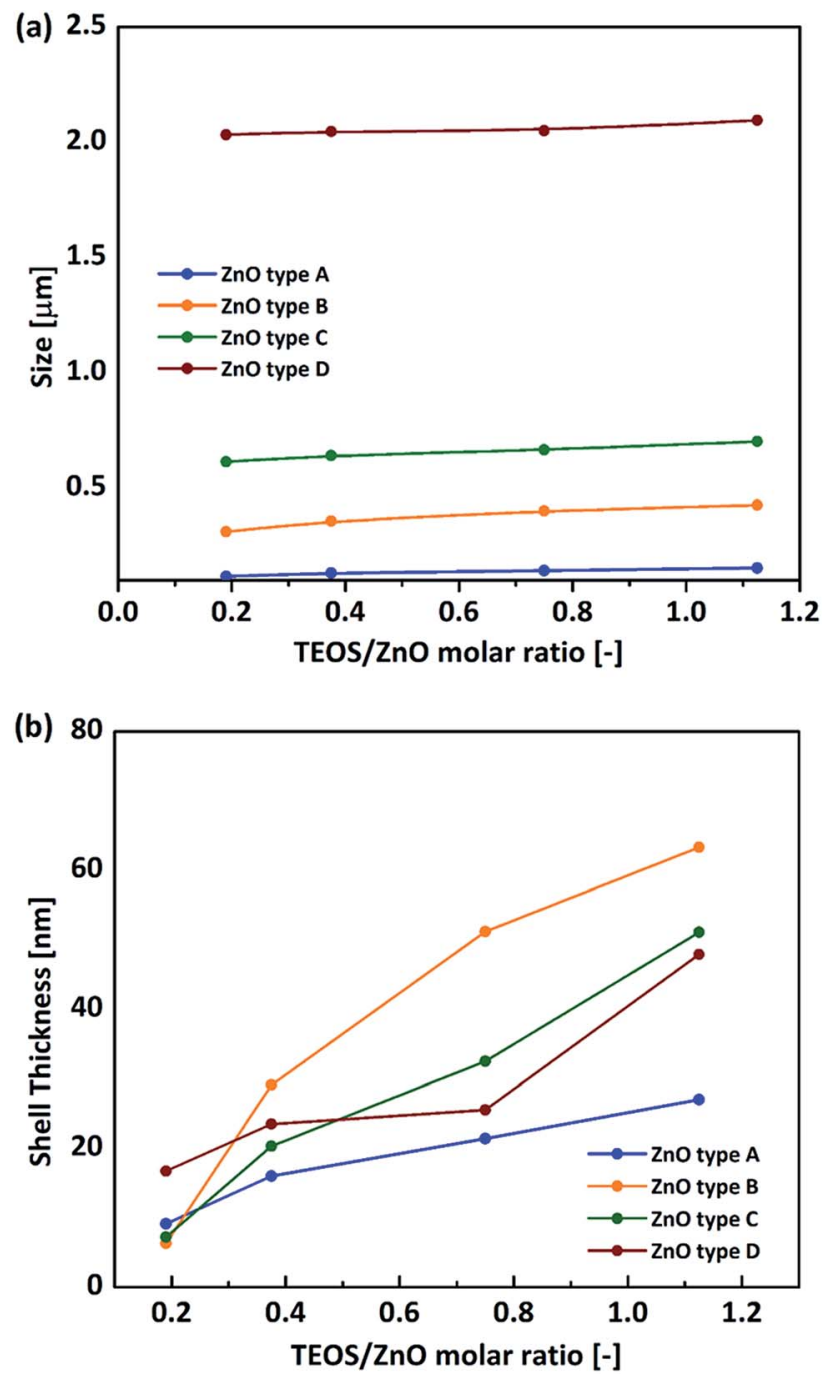

Fig. 3 Effect of ZnO template on HHSP size (a) and HHSP shell thickness (b) for different TEOS/ZnO molar ratio.

Fig. 2(a0) shows that the type A ZnO template particles existed in an agglomerated state, even after being subjected to ultrasonication. Consequently, HHSP particles synthesized using the type A ZnO template were also agglomerated. The other $\mathrm{ZnO}$ templates shown in Fig. 2(b0-d0) were better dispersed after ultrasonication, so yielded more disperse HHSP particles.

The average size and size distribution of the HHSP particles depended on those of the template particles used. As shown in Fig. 3(a), the HHSP particle size increased with increasing $\mathrm{ZnO}$ template size. The average HHSP particle size increased from $0.11 \mu \mathrm{m}$ to $2.1 \mu \mathrm{m}$ as the $\mathrm{ZnO}$ particle size increased from 0.1 $\mu \mathrm{m}$ to $2 \mu \mathrm{m}$. The size distributions of the HHSP particles for different template sizes are shown in Fig. S2 (ESI $\dagger$ ).

The HHSP shell thickness could be controlled by tuning the TEOS concentration. ${ }^{25}$ More $\mathrm{SiO}_{2}$ was formed on the $\mathrm{ZnO}$ surface with increasing TEOS concentration, resulting in a thicker shell and hence larger HHSP particles. The HHSP shell thickness increased from $6.3 \mathrm{~nm}$ to $63.3 \mathrm{~nm}$ as the TEOS/ZnO molar ratio increased from 0.2 to 1.125 . The effect of TEOS concentration on the HHSP shell thickness is shown in Fig. 3(b). No solid silica spheres were observed for this TEOS concentration range when using $\mathrm{ZnO}$ type A or type $\mathrm{B} \mathrm{ZnO}$ templates. This implied that the secondary homogenous nucleation of TEOS could be avoided within this range of TEOS/ZnO molar ratios. The importance of the TEOS/ZnO molar ratio for forming hollow structures can be illustrated by the diffusion-controlled nucleation concept. Increasing the TEOS concentration up to supersaturation led to the formation of a hollow structure. Further increasing the TEOS concentration above supersaturation would promote secondary nucleation to form independent dense $\mathrm{SiO}_{2}$ particles. ${ }^{26} \mathrm{~A}$ detailed explanation of this is provided in the ESI. The optimum TEOS/ZnO molar ratio was determined to be approximately 1.125 , as shown in Fig. S3 (ESI†).

Contrary to the results when using $\mathrm{ZnO}$ type $\mathrm{A}$ and $\mathrm{B}$ templates, independent silica particles were observed in HHSP samples prepared using type $\mathrm{C}$ and $\mathrm{D} \mathrm{ZnO}$ templates, for the same TEOS/ZnO range used for the type $\mathrm{A}$ and $\mathrm{B}$ templates (Fig. 2(c1, c2 and d1-d4)). This was because the larger template particles had a lower specific surface area, and the driving force for heterogeneous nucleation was proportional to the available surface. Consequently, when a larger $\mathrm{ZnO}$ template was used with the same TEOS/ZnO molar ratio, the rate of homogeneous nucleation was higher than the rate of the attachment of TEOS nuclei on the $\mathrm{ZnO}$ surface.

The optical transmittances of the various HHSP samples were examined to investigate the effects of shell thickness and particle size on the optical properties. The measurement was conducted in the wavelength range of 300-800 nm using $2 \mathrm{mg}$ $\mathrm{ml}^{-1}$ dispersions of HHSP samples synthesized using type B, type $\mathrm{C}$, and type $\mathrm{D} \mathrm{ZnO}$ templates. The results are shown in Fig. 4. HHSP samples were synthesized using these three $\mathrm{ZnO}$ templates, and the thinnest shells of the resulting HHSP samples were $6.3 \mathrm{~nm}, 7.2 \mathrm{~nm}$, and $16.7 \mathrm{~nm}$, respectively. The HHSP samples exhibited high transmittances with maximum values of approximately 99\%. The transmittance increased with decreasing shell thickness, as less scattered light was absorbed by the thinner shell. All HHSP samples exhibited higher transmittances than that of dense $\mathrm{SiO}_{2}$.

Besides shell thickness, the cavity size also affected the transmittance. For a similar shell thickness (approximately 51 $\mathrm{nm}$ ), HHSP particles with a smaller cavity (type B) exhibited a higher transmittance than HHSP particles with a larger cavity (type C). The sizes of the HHSP particles were comparable to the wavelength. Thus, the dependence of light scattering behaviour on the shell thickness and cavity size can be explained by the Rayleigh-Gans approximation for backscattering behaviour. This approximation suggests that the cross-sectional backscattering is related to the dimensional element, such as diameter and shell thickness, where a smaller diameter has a lower backscattering. ${ }^{27}$ Reduced backscattering implies higher transmittance. The thinner shell, coupled with a smaller cavity, led to an increase in the transport of mean free path, which substantially increased the transmittance and reduced backscattering. ${ }^{28}$

The HHSP particles showed higher transmittances than those of most other hollow morphologies, even with similar 

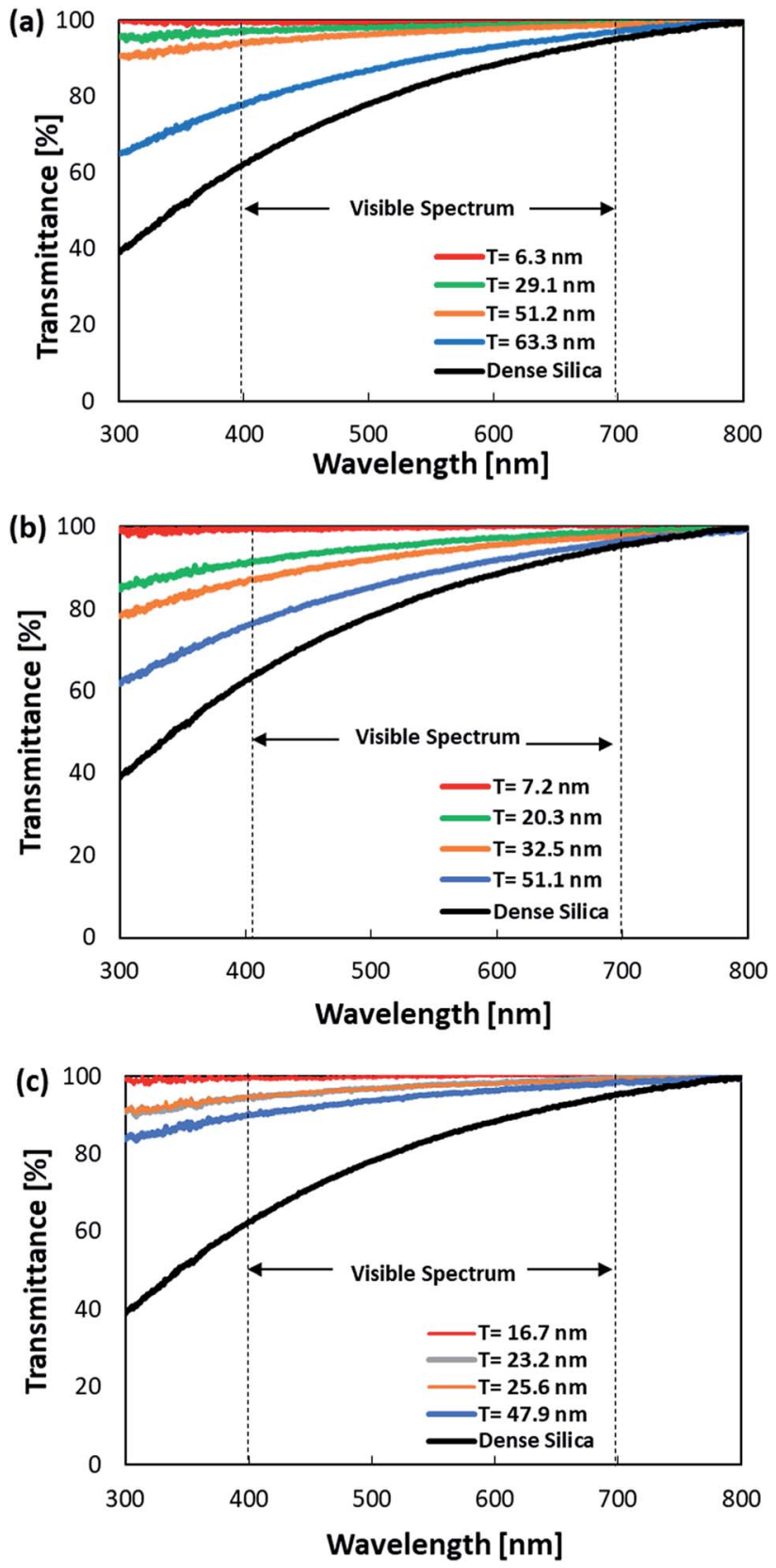

Fig. 4 Optical transmittance spectra of HHSP samples with different shell thicknesses prepared from type $B(a)$, type $C(b)$, and type $D(c)$ $\mathrm{ZnO}$ templates.

shell thicknesses (a detailed comparison is given in Table S1 $\left(\mathrm{ESI}_{\dagger} \dagger\right){ }^{6,10,12}$ As also described by the Rayleigh-Gans approximation, the backscattering behaviour at different wavelengths is affected by the orientation of the optical axis. This is one possible explanation for the differences in the backscattering between isotropic shapes such as spheres and anisotropic shapes such as plates and disks. Correlations between the geometrical anisotropy and optical properties of semiconductors need to be further studied. However, our preliminary results suggest that structuring $\mathrm{SiO}_{2}$ particles into hollow anisotropic structures, such as hollow plates, effectively improves optical transmittance in both the visible and ultraviolet regions. The transmittance characteristics in the visible and ultraviolet range can be adjusted by changing the shell thickness and cavity size. Therefore, the synthesized HHSP particle is a good candidate for future transparent films.

\section{Conclusions}

In summary, we prepared an anisotropic HHSP structure with high transmittance of ultraviolet and visible light, by microwave irradiation using $\mathrm{ZnO}$ as a template. The HHSP particles had a uniform shell thickness. The size and shell thickness could be controlled in the ranges of 6.3-63.3 $\mathrm{nm}$ and $0.11-2.1 \mu \mathrm{m}$, respectively, by changing the $\mathrm{ZnO}$ template size and TEOS concentration. The growth of the shell on the $\mathrm{ZnO}$ template involved the classical diffusion-controlled nucleation of TEOS. The template size and TEOS/ZnO molar ratio had a significant role in minimizing homogeneous nucleation. HHSP particles with the thinnest shell exhibited high visible and ultraviolet light transmittance of approximately 99\%. This value was higher than that for hollow silica spheres with the same shell thickness. These results indicate the geometrical dependence of the optical properties of semiconductor materials. The HHSP particles with high transmittance have potential as ultra-high transparency films in optical devices.

\section{Conflicts of interest}

The authors have no conflicts to declare.

\section{Acknowledgements}

The authors thank the Ministry of Research, Technology, and Higher Education of the Indonesia Government for providing a doctoral scholarship and research grant through the Program Magister Doktor Sarjana Unggul (L. Q.) under Contract No. 128/ SP2H/PTNBH/DRPM/2018. This work was supported by JSPS KAKENHI Grant Numbers 26709061 and 16K13642 and was partly supported by the Center for Functional Nano Oxides at Hiroshima University.

\section{References}

1 J. S. Yu, S. B. Yoon, Y. J. Lee and K. B. Yoon, J. Phys. Chem. B, 2005, 109, 7040-7045.

2 S. Machida, T. Yoshida, R. Hashimoto and M. Ogawa, J. Colloid Interface Sci., 2014, 420, 66-69.

3 T. Ogi, A. B. D. Nandiyanto and K. Okuyama, Adv. Powder Technol., 2014, 25, 3-17.

4 S. Cao, Z. Zhao, X. Jin, W. Sheng, S. Li, Y. Ge, M. Dong, W. Wu and L. Fang, J. Mater. Chem., 2011, 21, 19124.

5 D. Li, Y. Zhu and C. Mao, J. Mater. Chem. B, 2013, 1, 5515. 6 L. Ernawati, T. Ogi, R. Balgis, K. Okuyama, M. Stucki, S. C. Hess and W. J. Stark, Langmuir, 2016, 32, 338-345.

7 C. Tao, H. Yan, X. Yuan, C. Yao, Q. Yin, J. Zhu, W. Ni, L. Yan and L. Zhang, Colloids Surf., A, 2016, 501, 17-23. 
8 Y. Du, L. E. Luna, W. S. Tan, M. F. Rubner and R. E. Cohen, ACS Nano, 2010, 4, 4308-4316.

9 X. Zhang, P. Lan, Y. Lu, J. Li, H. Xu, J. Zhang, Y. Lee, J. Y. Rhee, K. L. Choy and W. Song, ACS Appl. Mater. Interfaces, 2014, 6, 1415-1423.

10 J. Xu, Y. Liu, W. Du, W. Lei, X. Si, T. Zhou, J. Lin and L. Peng, Thin Solid Films, 2017, 631, 193-199.

11 C. S. S. R. Kumar, UV-VIS and Photoluminescence Spectroscopy for Nanomaterials Characterization, 2013.

12 W. Suthabanditpong, C. Takai, M. Fuji, R. Buntem and T. Shirai, Phys. Chem. Chem. Phys., 2016, 18, 16293-16301.

13 M. Fuji, T. Shin, H. Watanabe and T. Takei, Adv. Powder Technol., 2012, 23, 562-565.

14 W. Zhao, M. Lang, Y. Li, L. Li and J. Shi, J. Mater. Chem., 2009, 19, 2778.

15 K. Han, Z. Zhao, Z. Xiang, C. Wang, J. Zhang and B. Yang, Mater. Lett., 2007, 61, 363-368.

16 K. W. Hu, K. C. Hsu and C. S. Yeh, Biomaterials, 2010, 31, 6843-6848.

17 Y. Chen, X. Xue and T. Wang, Nanotechnology, 2005, 16, 1978-1982.

18 L. Dai, X. L. Chen, X. Zhang, T. Zhou and B. Hu, Appl. Phys. A: Mater. Sci. Process., 2004, 78, 557-559.
19 W. Lou Xiong, C. Yuan, Q. Zhang and L. A. Archer, Angew. Chem., Int. Ed., 2006, 45, 3825-3829.

20 S. I. R. Castillo, S. Ouhajji, S. Fokker, B. H. Erné, C. T. W. M. Schneijdenberg, D. M. E. Thies-Weesie and A. P. Philipse, Microporous Mesoporous Mater., 2014, 195, 75-86.

21 A. F. Arif, Y. Kobayashi, R. Balgis, T. Ogi, H. Iwasaki and K. Okuyama, Carbon, 2016, 107, 11-19.

22 W. Widiyastuti, I. Maula, T. Nurtono, F. Taufany, S. Machmudah, S. Winardi and C. Panatarani, Chem. Eng. J., 2014, 254, 252-258.

23 I. A. Siddiquey, T. Furusawa, M. Sato and N. Suzuki, Mater. Res. Bull., 2008, 43, 3416-3424.

24 N. M. Bahadur, T. Furusawa, M. Sato, F. Kurayama, I. A. Siddiquey and N. Suzuki, J. Colloid Interface Sci., 2011, 355, 312-320.

25 N. Hagura, W. Widiyastuti, F. Iskandar and K. Okuyama, Chem. Eng. J., 2010, 156, 200-205.

26 A. F. Arif, S. Taniguchi, T. Izawa, K. Kamikubo, H. Iwasaki and T. Ogi, ACS Omega, 2018, 3, 2-8.

27 H. R. Gordon, Opt. Express, 2007, 15, 5572-5588.

28 L. A. Fielding, O. O. Mykhaylyk, A. Schmid, D. Pontoni, S. P. Armes and P. W. Fowler, Chem. Mater., 2014, 26, 1270-1277. 